\title{
METABOTROPHIC EFFECTS OF AEROBIC TRAINING IN MALE PATIENTS WITH METABOLIC SYNDROME
}

\author{
Karim Azali Alamdari ${ }^{1}$ and Siroos Choobineh ${ }^{2}$ \\ 'Department of Physical Education and Sport Sciences, Faculty of Education and Psychology, \\ Azarbaijan Shahid Madani University, Tabriz, Iran \\ ${ }^{2}$ Faculty of Physical Education and Sport Sciences, University of Tehran, Tehran, Iran
}

\begin{abstract}
We investigated the integrated effects of an aerobic training program on circulatory levels of the metabotrophic factors (metabotrophins) nerve growth factor (NGF), brain derived neurotrophic factor (BDNF) and insulin like growth factor-1 (IGF-1), and anabolic state (testosterone/cortisol ratio) in middle aged males with metabolic syndrome (MetS). Thirty subjects (age: 58.23 \pm 5.25 years, weight: $95.00 \pm 8.26 \mathrm{~kg}$, height: $\left.173 \pm 7.03 \mathrm{~cm}, \mathrm{VO}_{2 \text { peak }}: 19.96 \pm 4.18 \mathrm{ml} \mathrm{kg} . \mathrm{min}-1\right)$ were randomized into exercise $(n=16)$ and control, non-exercised $(n=14)$ group. The exercise group participated in eight weeks of aerobic training program (3 sessions/week at $50 \%-60 \%$ of $\mathrm{VO}_{2}$ peak). Fasting blood samples were taken at baseline and after training and $\mathrm{VO}_{2}$ peak, insulin sensitivity and an overall metabolic syndrome $Z$ score (Z MetS) were calculated. Aerobic training significantly increased insulin sensitivity, Vo2 peak, plasma HDL and serum levels of NFG, BDNF, IGF-1 and testosterone $(\mathrm{P}<0.05)$ as compared to control patients. Additionally, there were significant decreases in body weight, mean atrial pressure, waist circumference, plasma glucose and triglyceride and also serum cortisol levels $(\mathrm{P}<0.05)$ in training patients. Body weight, waist circumference, and NGF levels were recognized as the most important predictors for the $80 \%$ of variability in serum testosterone/cortisol ratio $(P<0.05)$. An integrated metabotrophic and anabolic effect of aerobic training in patients with MetS was established. Early measurement of these variables may have prognostic benefits for at risk population who progress to the generalized stage of cardiometabolic abnormalities.
\end{abstract}

Adipobiology 2015, 7:21-29

Key words: exercise, metabolic syndrome, cardiometabolic risk, metabotrophic factors, NGF, BDNF, IGF-1, testosterone 


\section{Introduction}

In accordance with the United States National Cholesterol Education Program's Adult Treatment Panel III (ATP III) the metabolic syndrome (MetS) is a cluster of cardiometabolic risk factors in one individual, including elevated blood pressure, dyslipidemia, impaired glycemic control, and abdominal obesity $(1,2)$. A high prevalence of MetS is repeatedly observed in patients with a low testosterone level and the reduced testosterone can adversely affect many of MetS components (3). Therefore, an increased attention was recently directed to clarify the probability of a disbalanced serum testosterone as a risk factor for MetS (4).

On the other hand, the classical neurotrophins nerve growth factor (NGF) and brain-derived neurtrophic factor (BDNF) were recently also recognized to mediate metabotrophic effects on glucose, lipid and energy homeostasis (5-7). Accordingly, a metabotrophic deficit due to the reduced circulating levels of NGF and BDNF was implicated in the pathogenesis of advanced MetS $(7,8)$. Circulatory metabotrophins can also be influenced by stressful events (9) which preceded the increased cortisol levels (10). In a recent review it was concluded that chronic exercise may decrease the serum cortisol level in older people and recommended that future studies should seek to determine possible types of exercise to decrease cortisol levels in those with cardiometabolic diseases (11).

Additionally, insulin-like growth factor-1 (IGF-1) as a protein with neurotrophic (12) and insulin-like, metabolic (13) properties is also considered to be of major importance for mediating the benefits of physical activity on the health status and metabolism as well as other neurotrophic factors $(14,15)$. Therefore, it is expected that the consequence of metabolic, neurotrophic and anabolic effects of exercise could be manifested in circulating IGF-1. IGF-1 levels was found to be consistently reduced in individuals with MetS and/or its components and its reduction could potentially impact on risk for MetS (16).

Clinical intervention studies have also revealed that aerobic training clearly decreases cardiometabolic risk factors $(17,18)$. However, whether the metabotrophic reserve of the organism is influenced by the effects of aerobic training on MetS components still remains to be elucidated. On that background, we investigated whether a link between testosterone/cortisol ratio, an overall state of MetS and serum level of NGF, BDNF and IGF- 1 could exist in middle aged man and how an aerobic training program could modify these variables?

\section{Subjects and Methods}

The study was approved by the local ethics committee of the University of Tehran (Clinical Trial ID: 2099660, Date:
7/11/2013) and performed according to the principles of the Declaration of Helsinki. The study was started after signing an informed consent document for participation in the research study by all the subjects.

Thirty volunteer sedentary obese middle aged (50-65 years) men underwent physical and clinical screens. The mean arterial pressure (MAP), electrocardiogram (ECG), fasting blood sugar (FBS), blood lipid profile, creatinine, and complete blood count (CBC) were monitored. Waist circumference of $\geq 91.5$ $\mathrm{cm}$ was obligatory for a diagnosis of MetS (19). In addition to abdominal obesity, any 2 of the following 3 abnormalities should be observed: (i) dyslipidemia: triglyceride level $\geq 150 \mathrm{mg} / \mathrm{dL}$ or HDL cholesterol level $<40 \mathrm{mg} \mathrm{dL}-1$ or use of antidyslipidemia medication, (ii) hypertension: systolic blood pressure $\geq 130$ $\mathrm{mm} \mathrm{Hg}$ or diastolic blood pressure $\geq 85 \mathrm{~mm} \mathrm{Hg}$ or use of antihypertensive medication, and (iii) hyperglycemia: fasting plasma glucose level $\geq 110 \mathrm{mg} / \mathrm{dL}$ or use of hypoglycemia medication.

Exclusion criteria were smoking, alcohol drinking, sleep disorders, current insulin therapy; changes during the previous two months in oral hypoglycemic, antihypertensive, or lipidlowering agents or body weight (5\%); serum creatinine level of $(2.26 \mathrm{mg} / \mathrm{dL})$ or greater; proteinuria greater than $1 \mathrm{~g}$ day- 1 ; blood pressure greater than 160/100 $\mathrm{mmHg}$; restrictions in physical activity because of disease or presence of other problems. Some of the participants were taking a range of medications, including beta blockers $(n=5)$, statins $(n=5)$, and metformin $(n=4)$.

Study protocol: The subjects were divided randomly into two groups including exercise ( $\mathrm{N}=16$, Weight: $94.31 \pm 7.80 \mathrm{~kg}$, Height: $173 \pm 6.8 \mathrm{~cm}$, Age: $57.93 \pm 5.14$ yrs. $)$ and control $(\mathrm{N}=14$, Weight: $95.78 \pm 7.97 \mathrm{~kg}$, Height: $173 \pm 7.4 \mathrm{~cm}$, Age: $55.78 \pm 5.36$ yrs.). Their characteristics are shown in Table 1. All the subjects performed a graded exercise test (GXT) to exhaustion level to determine their VO2 peak by standard method explained elsewhere (20). Waist circumference (WC), weight and height were measured using standard techniques. Blood pressure was recorded using a standard mercury sphygmomanometer on three occasions separated by intervals of 2 minutes; the average of the last two measures was used in the analysis.

Fasting blood samples were taken at baseline and after training (the second sample was taken 15 hours after the last training session). Plasma FBS, HDL cholesterol, and triglyceride levels were determined by enzymatic kits (Parsazmun, Karaj, Iran). Serum BDNF, NGF, IGF-1 and insulin were assayed in duplicate according to the manufacturers' instructions (BDNF ELISA kit, R\&D Systems, Minneapolis, Minnesota; NGF DuoSet ELISA kit, R\&D Systems; IGF-1 Quantikine ELISA kit, R\&D Systems; Insulin Diagnostic Related Groups ELISA 
Table 1. Subject characteristics and description of the variables

\begin{tabular}{|c|c|c|c|c|}
\hline \multirow[b]{2}{*}{ Factor } & \multicolumn{2}{|c|}{ Control $(n-=14)$} & \multicolumn{2}{|c|}{ Exercise $(n-=14)$} \\
\hline & Baseline & After Training & Baseline & After Training \\
\hline Weight & $95.78 \pm 7.97$ & $95.57 \pm 7.83$ & $94.31 \pm 8.70$ & $92.12 \pm 8.28$ * \\
\hline Body Mass index $\left(\mathrm{kg} \mathrm{m}^{2}-1\right)$ & $31.65 \pm 1.66$ & $31.59 \pm 1.73$ & $31.36 \pm 1.33$ & $30.65 \pm 1.55 *$ \\
\hline Relative VO2 peak (mL kg.min-1) & $20.14+4.24$ & $19.92+3.91$ & $19.81+4.27$ & $23.43+4.97^{*}$ \\
\hline Waist circumference $(\mathrm{cm})$ & $106.85 \pm 6.50$ & $106.28 \pm 6.55$ & $106 \pm 5.41$ & $101.75 \pm 4.66^{*}$ \\
\hline Mean Arterial Pressure $(\mathrm{mmHg})$ & $105.30 \pm 7.83$ & $102.13 \pm 7.29$ & $106.18 \pm 6.76$ & $100.29 \pm 5.81 *$ \\
\hline Fasting blood sugar (mg dl-1) & $128.00 \pm 24.92$ & $123.64 \pm 22.23$ & $124.05 \pm 22.62$ & $110.96 \pm 16.79 *$ \\
\hline Triglyceride (mg dl-1) & $227.85 \pm 77.16$ & $240.92 \pm 76.05$ & $222.43 \pm 80.84$ & $196.56 \pm 82.38^{*}$ \\
\hline High density lipoprotein (mg dl-1) & $39.25 \pm 6.28$ & $37.06 \pm 6.8$ & $38.31 \pm 5.04$ & $45.31 \pm 8.45^{*}$ \\
\hline Brain-derived neurotrophin factor (pg mL-1) & $1838.62 \pm 324.17$ & $1854.46 \pm 343.13$ & $1674.15 \pm 526.98$ & $1744.59 \pm 504.68^{*}$ \\
\hline Insulin like growth factor-1 (ng mL-1) & $135 \pm 38.80$ & $136.14 \pm 33.22$ & $128.81 \pm 40.24$ & $153.18 \pm 41.34^{*}$ \\
\hline Nerve growth factor (pg mL-1) & $63.97 \pm 22.38$ & $68.71 \pm 20.26$ & $64.27 \pm 21.82$ & $95.24 \pm 27.15^{*}$ \\
\hline Testeterone (ng dL-1) & $3.75 \pm 1.09$ & $3.92 \pm 1.13$ & $3.91 \pm 1.01$ & $5.12 \pm 1.45^{*}$ \\
\hline Cortisol (nmol L-1) & $337.64 \pm 100.66$ & $335.85 \pm 86.69$ & $332.62 \pm 96.67$ & $304.18 \pm 77.92 *$ \\
\hline Testeterone/ Cortisol & $0.0118 \pm 0.0045$ & $0.0123 \pm 0.0042$ & $0.0128 \pm 0.0052$ & $0.0182 \pm 0.006^{*}$ \\
\hline Overall MetS z Score & $4.78 \pm 2.37$ & $4.78 \pm 2.43$ & $5.44 \pm 2.20$ & $1.66 \pm 2.64$ * \\
\hline Insulin $(\mu \mathrm{lU} / \mathrm{ml})$ & $20.13 \pm 3.09$ & $19.38 \pm 2.49$ & $20.12 \pm 4.76$ & $19.81 \pm 4.60$ \\
\hline HOMA index & $6 . .05 \pm 1.38$ & $5.56 \pm 0.97$ & $6.46 \pm 2.06$ & $5.79 \pm 2.03 *$ \\
\hline Average Daily caloric intake & $2234.76 \pm 386.36$ & $2205 \pm 353.72$ & $2183.41 \pm 403.81$ & $2086.79 \pm 222.45$ \\
\hline Daily Calories from proteins & $508.50 \pm 161.53$ & $528 \pm 150.45$ & $560.27 \pm 189.30$ & $572.58 \pm 106.43$ \\
\hline Calories from carbohydrates & $1108 \pm 232.85$ & $1111.92 \pm 222.78$ & $1118.47 \pm 186.72$ & $1089.22 \pm 140.09$ \\
\hline Daily Calories from lipids & $618.26 \pm 180.53$ & $580.07 \pm 157.39$ & $504.66 \pm 212.64$ & $466.85 \pm 166.61$ \\
\hline
\end{tabular}

Values are given as mean (S.D.). ${ }^{*} \mathrm{P}<0.05$ versus baseline in Exercise group

kit, Hamburg, Germany). Cortisol and total testosterone were assayed using commercial kits (Diagnostic Systems Laboratories, Webster, TX). For total testosterone, the minimum detection limit was $0.03 \mathrm{nmol} / \mathrm{L}$; intraassay and interassay CVs for three different concentrations were less than $9.6 \%$ and less than $9.1 \%$, respectively.

A modified Z score (overall MetS Z score) was calculated for each variable using individual subject data, the United States National Cholesterol Education Program's Adult Treatment Panel (ATP) III criteria, and standard deviations using data from the both groups at each step (21). The equation used to calculate the MetS Z score at baseline for exercise group was as follows:

Overall MetS Z-Score $($ Zmets $)=[(40-\mathrm{HDL}) / 5.04]+[(\mathrm{TG}$ $-150) / 80.84]+[($ fasting blood glucose -110$) / 22.62]+[($ waist circumference -91.5$) / 5.41]+[($ mean arterial pressure 100)/6.76].

Sum of the number of ATP III criteria met (without rely on medication use) in the baseline and after training was determined for each subject (21). To estimate overall insulin sensitivity, the homeostasis assessment model (HOMA index) was used.

Participants received a kitchen scale (Model: Hedieh, IRAN) and recorded their diet in detail for two weekdays and a weekend day (three and one week prior to the study beginning and also at 4 th and 6 th weeks. The logs were analyzed by Nutrition analyzer software N4.

The exercise group followed an 8-week aerobic training program (3 sessions per week; 25-40 minutes walking, running by $50 \%-60 \%$ of the heart rate measured at VO2 peak point in 
GXT (totally $123.17 \pm 9.17 \mathrm{~km}$, adherence to training: 88.34 $\pm 7.85 \%)$. Training sessions were performed in the Exercise Physiology Laboratory at the same time of day (4-6 pm), beginning with $10 \mathrm{~min}$ warm-up and ending with $10 \mathrm{~min}$ cooldown. Heart rate monitors (Polar Electro Oy, Kempele, Finland) were used to adjust workload to achieve the target heart rate. Participants progressed from 25 minute/session at $50 \%$ of the VO2 peak to $40 \mathrm{~min} /$ session at $60 \%$ of the $\mathrm{VO} 2$ peak. Individual exercise supervision was provided for each session. All exercise training sessions were supervised by study staff, and all the subjects exercised for a similar amount of time.

Statistical analysis: Pearson correlation coefficient was used to assess correlations between the variables. All baseline variables were compared between exercise and control groups by means of independent samples $\mathrm{T}$ test. By using $2 \times 2$ repeated measure ANOVA, we tested the effects of training over the time between each of two groups. A stepwise multiple regression analysis was performed to identify the independent predictors of testosterone/cortisol ratio and Zmets. Statistical significance was set at $\mathrm{P}<0.05$ and all analyses were performed using the SPSS/PC package.

\section{Results}

No significant intergroup differences were observed at baseline variables $(\mathrm{P}>0.05)$. Correlation analysis showed significant relationships between testosterone/cortisol ratio with weight $(\mathrm{r}=-0.64, \mathrm{P}=0.001)$, waist circumference $(\mathrm{r}=-0.76, \mathrm{P}=0.001)$ NGF $(r=0.65, P=0.001)$, IGF-1 $(r=0.60, P=0.001)$, Insulin $(r=$ $-0.63, \mathrm{P}=0.001)$ and HOMA-IR $(\mathrm{r}=-0.62, \mathrm{P}=0.001)$, but not to Zmets $(\mathrm{r}=-0.18, \mathrm{P}=0.32)$, age $(\mathrm{r}=-0.22, \mathrm{P}=0.22)$, $\mathrm{BMI}(\mathrm{r}=-0.20$, $\mathrm{P}=0.27), \operatorname{Vo} 2 \operatorname{peak}(\mathrm{r}=0.27, \mathrm{P}=0.14)$ and $\mathrm{BDNF}(\mathrm{r}=0.26, \mathrm{P}=0.15)$ in whole population at baseline. Further analysis indicated that $\mathrm{Z}$ MetS was related to insulin $(\mathrm{r}=0.37, \mathrm{P}=0.44)$, Mean Arterial Pressure $(r=0.45, P=0.12)$, waist circumference $(r=0.45, P=0.12)$, fasting blood sugar $(\mathrm{r}=0.53, \mathrm{P}=0.002)$, triglyceride $(\mathrm{r}=0.50$, $\mathrm{P}=0.004)$, but not to other variables $(\mathrm{P}>0.05)$. In a multiple linear regression analysis on baseline variable in which age, height, weight, BMI, BDNF, NGF, IGF-1, Insulin, HOMA-IR, Mean Arterial Pressure, waist circumference, fasting blood sugar, triglyceride, HDL cholesterol, and overall Z MetS were included as independent variables, waist circumference(Beta $=-0.59$, $\mathrm{p}=0.001)$, NGF (Beta=-0.3, $\mathrm{p}=0.013$ ) and weight (Beta $=-0.27$, $\mathrm{p}=0.023$ ), explained $80 \%$ of testosterone/cortisol ratio variability (SD of the estimate $=0.0021, \mathrm{P}=0.001$ ).

Aerobic training not only significantly increased insulin sensitivity, Vo2 peak, serum NGF, BDNF, IGF=1 and testosterone; but also decreased all the metabolic risk factors, body weight, $\mathrm{Z}$ MetS, and serum cortisol level $(\mathrm{P}<0.05)($ Table 1,2$)$.

\section{Discussion}

The results of the present study showed that exercise positively affects cardiometabolic risk factors, which is consistent with

Table 2. Frequencies of the cardiometabolic risk factors

\begin{tabular}{|c|c|c|c|c|c|c|c|c|}
\hline \multirow[b]{3}{*}{ No. of Total Metabolic Risk Factors } & \multicolumn{4}{|c|}{ Control $(\mathrm{N}=14)$} & \multicolumn{4}{|c|}{ Exercise $(\mathrm{N}=16)$} \\
\hline & \multicolumn{2}{|c|}{ Baseline } & \multicolumn{2}{|c|}{ After Training } & \multicolumn{2}{|c|}{ Baseline } & \multicolumn{2}{|c|}{ After Training } \\
\hline & & 56 & & 55 & & 67 & & 44 \\
\hline & Count & $\%$ & Count & $\%$ & Count & $\%$ & Count & $\%$ \\
\hline Subjects with 1 Risk Factors & 0 & 0 & 0 & 0 & 0 & 0 & 3 & 18.8 \\
\hline Subjects with 2 Risk Factors & 0 & 0 & 1 & 7.11 & 0 & 0 & 3 & 18.8 \\
\hline Subjects with 3 Risk Factors & 3 & 21.4 & 2 & 14.3 & 1 & 6.3 & 6 & 37.5 \\
\hline Subjects with 4 Risk Factors & 8 & 57.1 & 8 & 57.1 & 11 & 68.8 & 3 & 18.8 \\
\hline Subjects with 5 Risk Factors & 3 & 21.4 & 3 & 21.4 & 4 & 25 & 1 & 6.3 \\
\hline Subjects with WC>91.5 cm & 14 & 100 & 14 & 100 & 16 & 100 & 16 & 100 \\
\hline Subjects with TG >150 mg dL-1 & 12 & 85.7 & 13 & 92.9 & 14 & 87.5 & 10 & 62.5 \\
\hline Subjects with $\mathrm{HDL}<40$ mg dL-1 & 11 & 78.6 & 10 & 71.4 & 13 & 81.3 & 4 & 25 \\
\hline Subjects with $B P>130 / 85 \mathrm{mmHg}$ & 10 & 71 & 9 & 64 & 12 & 75 & 8 & 50 \\
\hline Subjects with FBS> $110 \mathrm{mg} \mathrm{dL-} 1$ & 9 & 64.3 & 9 & 64.3 & 12 & 75 & 6 & 37.5 \\
\hline
\end{tabular}


previous studies (20) and emphasized on protective effects of aerobic training and clinical importance. Based on the negative relationships between baseline testosterone/cortisol ratio and body weight, waist circumference, insulin and HOMA-IR in whole population, we speculated that testosterone/cortisol ratio reduces with severity of obesity and insulin resistance in MetS subjects. In our study waist circumference was also recognized as the most important predictor of testosterone/cortisol ratio variability. Recently, among metabolic components for MetS, obesity has gained the most increased attention as a key symptom causing hypogonadism. Large cross-sectional surveys have also shown that the inverse association of testosterone with individual components of the MetS was the strongest for central adiposity and that among multiple health variables, increased waist circumference was the most closely associated with low testosterone (22). Other studies show that adiposity (23) and development of diabetes or the MetS accelerated the age-related decline in testosterone (24). Moreover, for most men early detection of a low serum testosterone (25) and/or NGF and BDNF (2) level was proposed to could be as the most reliable early marker for the eventual development of MetS. Of note, it is well known that during the discovery of NGF by Rita LeviMontalcini in the 1950's it was established that the castration of male rats resulted in a significant decrease of NGF secretion by submaxillary glands, a major rat source of NGF, that is, there is a positive correlation between testosterone and NGF levels (7, 8 and references therein).

Although the mechanism for an association of low testosterone circulating level and obesity remains unclear, elevation of serum leptin associated with obesity speculated to inhibit gonadotropinstimulated androgen production (26). Moreover, increase in the peripheral aromatization of testosterone in adipose tissue in obese men also may be associated with low serum testosterone level through the feedback inhibition of pituitary luteinizing hormone secretion caused by elevated estrogen level (4).

Both testosterone and testosterone/cortisol ratio were significantly increased in our study after aerobic training which could be explained to some extent by weight loss. It was demonstrated that weight loss leads to substantial increases in total testosterone, especially in morbidly obese men, proportional to the amount of weight loss (27). Additionally, one study suggested that even small weight loss in only mildly overweight men was significantly increased testosterone levels (28) This disproportionate increase in testosterone levels relative to weight loss may have occurred because weight loss was achieved by exercise. Several uncontrolled studies have shown that exercise itself can increase testosterone by up to $30 \%$ (29).
The declined cortisol level after training is another factor can explain an increased testosterone/cortisol ratio in this period. Patients with MetS has been found to have a state of "functional hypercortisolism" (11) and the higher cortisol in adipose tissue and liver might contribute to the development of several features of the MetS (30). A recent review was concluded that chronic exercise (mostly resistance exercises) may have positive influence on serum cortisol level in older people (11). However, little attention has been directed to the effects of aerobic training. Only two studies investigated old people and no statistically significant changes in cortisol were observed in response to training $(31,32)$. The exact mechanisms for declined cortisol level after training are still not understood well. Increased visceral adipose tissue leads to increased secretion of proinflammatory cytokines, estradiol, insulin, and leptin, all of which may inhibit the activity of the hypothalamicpituitary-adrenal (HPA) axis at multiple levels (33). Therefore, it seems that decreased body fat could also be responsible to some extent for decreased cortisol level after aerobic training. Some authors have emphasized that hormonal changes can be influenced by factors such as stress, anxiety, psychological status, and the economic status of individuals (34). Moreover, local regeneration of cortisol is reported to be higher in adipose tissue of MetS patients with minimal effects on circulating levels (30). Therefore, including these variables can help control for these factors, and help researchers understand the mechanisms by which exercise influences the levels of serum cortisol (32)

In another part, serum insulin level was unchanged after aerobic training, while a declined HOMA-IR was observed. It could be indicated on improved glucose entrance to cells via exercise induced mechanisms (35) in our obese subjects with MetS who were highly insulin resistant at baseline (the cut off point for diagnosis of insulin resistance based on HOMA-IR was described as $>2.5$ (36). Waist circumference and abdominal obesity were recognized as the best simple anthropometric indices of the abdominal visceral adipose tissue accumulation and related cardiometabolic risk (37). A bidirectional relationship between visceral fat and testosterone was found to promote insulin resistance via increased inflammatory cytokines (22) and other mechanisms involving muscle, liver and bones (22). Therefore, it seems that improved lifestyle factors or altered pharmacological management that increased testosterone levels also contributed to improved insulin sensitivity.

Further, we showed elevated serum IGF-1 after aerobic training. According to the existing evidence, the serum free IGF-I measurement was not always substantially altered after exercise (38) and the potential for this increase requires longer training duration (39). Circulating IGF-I is shown to be higher 
in fitter subjects and correlates with lean body mass (LBM) (38). The latter does not seem to change by our aerobic training, however, an elevated fitness level after training in exercise group $(\Delta \%=18.57 \pm 9.41)$ is helpful to explain the observed changes in serum IGF-I level. IGF-1 has neurotrophic properties (12) with insulin-like effects that reduce blood glucose levels (13). Therefore, its elevation after aerobic training seems to have a major importance on the neurocognitive function in MetS.

Both NGF and BDNF levels were also increased after aerobic training. There is controversial reports regarding the effects of aerobic training on serum BDNF in MetS and type 2 diabetes, ranging from an increased (40), decreased $(20,41)$ or not altered (42) level of circulatory BDNF. Nerve growth factor is synthesized and released by white adipocytes and the level of the mRNA is reported to be higher in obese patients (43). However; lower plasma NGF was also demonstrated in morbidly obese subjects (43). Recently Damirchi et al (20) were reported a decreased serum BDNF levels after aerobic training in MetS subjects. We attributed this controversy to the different MetS severity levels between two studies. In that research the cut off point for waist circumference was $>102 \mathrm{~cm}$ instead of $>91.5 \mathrm{~cm}$ in our study and they have not included medication use as a risk factor. Moreover, our subjects had higher overall MetS $\mathrm{Z}$ score and higher insulin resistance. Therefore, we speculated that our subjects were in a more generalized stages of MetS. Hristova and Aloe (44) suggested that in early stage MetS hyperneurotrophinemia may represent a compensatory mechanism against a metinflammatory state. However, in the advanced stage of MetS, these compensatory mechanisms fail and the resulted hyponeurotrophinemia may consequently contribute to the development of pathology of atherosclerosis and/or MetS $(2,7)$.

Plasma BDNF (45) and NGF (46) level has also found to decrease with age advancement and the exact reason for this decrease is still unclear. Considering that the prevalence of MetS, type 2 diabetes and obesity as individuals get older, it is possible that these metabotrophins' functions as protective factors against cardiometabolic and cognitive disorders (4750 ), renders individuals more susceptible to these conditions. Whereas exercise-induced alterations in NGF and BDNF levels may exert both neuro- and metabotrophic effects (51-53).

\section{Conclusion}

Taken as a whole, the results of this study emphasize on the metabotrophic effects of aerobic training for people with generalized MetS as it declines metabolic risk and serum cortisol, while increases NGF, BDNF, IGF-1 and testosterone. It seems early measurement of these variables could have prognostic benefits for at risk population who progress to generalized MetS stage. Future studies should follow similar works by additional investigations on adipose tissue-derived neuro-metabotrophic factors $(7,54)$.

Limitations in the present study. Our findings should only be applied to men. We measured, only the fasting blood samples at $8 \mathrm{AM}$, which probably do not reflect metabotrophins or steroids 24-hour and/or tissue levels, as an overexpression of steroids might be present in adipose tissue with minimal effect on circulation (34). Moreover, the circulatory neurotrophins might not to reflect their actual cellular processing in whole body, i.e. synthesis, release, utilization, and degradation. We did not collect any measures of visceral adipose tissue, inflammatory markers and cognitive function. The strengths of this study include a synchronal investigation on the effects of aerobic exercise on neurometabotrophins and corticosteroids in male MetS patients. We included an established cut off point for abdominal obesity in Iranian adults $(>91.5 \mathrm{~cm})$ as an obligatory criterion for MetS screening which enabled us to recruit more matched subjects as the classic methods (e.g. ATPIII criteria) may involve a spread spectrum of cardiometabolic risk factors (20).

\section{Acknowledgements}

This research was supported by grants from the Research Council of the University of Tehran. Gratitude is expressed to the subjects that participated in this study as well as to each of the assistants who were instrumental in the collection of the data.

\section{Conflict of interest}

The authors declare no conflict of interest.

\section{References}

1. Cornier M, Dabelea D, Hernandez T, Lindstrom R, Steig A, Stob N, et al. The metabolic syndrome. Endocr Rev 2008; 29:777. [DOI: 10.1210/er.2008-0024]

2. Chaldakov GN, Fiore M, Stankulov IS, Manni L, Hristova MG, Antonelli A, et al. Neurotrophin presence in human coronary atherosclerosis and metabolic syndrome: a role for NGF and BDNF in cardiovascular disease? Prog Brain Res 2004; 146:279-89. [DOI: 10.1016/S0079-6123(03)46018-4]

3. Salam R, Kshetrimayum AS, Keisam R. Testosterone and metabolic syndrome: The link. Indian J Endocrinol Metab 2012; (Suppl1):S12. [DOI: 10.4103/2230-8210.94248]

4. Tsujimura A, Miyagawa Y, Takezawa K, Okuda H, Fukuhara S, Kiuchi $\mathrm{H}$, et al. Is low testosterone concentration a risk factor for metabolic syndrome in healthy middle-aged men? Urology 2013; 82:814-819. [DOI: 10.1016/j.urology.2013.06.023] 
5. Gomez-Pinilla F, Vaynman S, Ying Z. Brain-derived neurotrophic factor functions as a metabotrophin to mediate the effects of exercise on cognition. Eur J Neurosci 2008; 28:2278-2287. [DOI: 10.1111/j.1460-9568.2008.06524.x]

6. Yamanaka M, Itakura Y, Ono-Kishino M, Tsuchida A, Nakagawa T, Taiji M. Intermittent administration of brainderived neurotrophic factor (BDNF) ameliorates glucose metabolism and prevents pancreatic exhaustion in diabetic mice. J Biosci Bioeng 2008; 105: 395-402. [DOI: 10.1263/ jbb.105.395]

7. Yanev S, Aloe L, Fiore M, Chaldakov GN. Neurotrophic and metabotrophic potential of nerve growth factor and brainderived neurotrophic factor: Linking cardiometabolic and neuropsychiatric diseases. World J Pharmacol 2013;2:92-99. [DOI: 10.5497/wjp.v2.i4.92]

8. Chaldakov GN, Aloe L. Homage to Rita Levi-Montalcini, the Queen of modern neuroscience. Biomed Rev 2012; 23: 1-7. [DOI: http://dx.doi.org/10.14748/bmr.v23.24]

9. Aloe L, Alleva E, Fiore M. Stress and nerve growth factor: findings in animal models and humans. Pharmacol Biochem Behav 2002;73:159-166. [DOI: 10.1016/S00913057(02)00757-8]

10. Givalois L, Naert G, Rage F, Ixart G, Arancibia S, TapiaArancibia L. A single brain-derived neurotrophic factor injection modifies hypothalamo-pituitary-adrenocortical axis activity in adult male rats. Mol Cell Neurosci 2004; 27:280-295. [DOI: 10.1016/j.mcn.2004.07.002]

11. Corazza DI, Sebastião É, Pedroso RV, Andreatto CAA, de Melo Coelho FG, Gobbi S, et al. Influence of chronic exercise on serum cortisol levels in older adults. Eur Rev Aging Phys Act 2014;11:25-34. [DOI: 10.1007/s11556-013-0126-8]

12. Hillman $\mathrm{CH}$, Erickson KI, Kramer AF. Be smart, exercise your heart: exercise effects on brain and cognition. Nat Rev Neurosci 2008;9:58-65. [DOI: 10.1038/nrn2298]

13. LeRoith D, Yakar S. Mechanisms of disease: metabolic effects of growth hormone and insulin-like growth factor 1. Nat Clin Pract Endocrinol Metab 2007;3:302-10. [DOI: 10.1038/ncpendmet0427]

14. Cotman CW, Berchtold NC, Christie L-A. Exercise builds brain health: key roles of growth factor cascades and inflammation. Trends Neurosci 2007;30:464-72. [DOI: 10.1016/j.tins.2007.06.011]

15. Carro E, Nuñez A, Busiguina S, Torres-Aleman I. Circulating insulin-like growth factor I mediates effects of exercise on the brain. J Neurosci 2000;20:2926-2933.

16. Akanji AO, Smith RJ. The insulin-like growth factor system, metabolic syndrome, and cardiovascular disease risk.
Metab Syndr Relat Disord 2012;10:3-13. [DOI: 10.1089/ met.2011.0083]

17. Frank LL, Sorensen BE, Yasui Y, Tworoger SS, Schwartz RS, Ulrich CM, et al. Effects of exercise on metabolic risk variables in overweight postmenopausal women: a randomized clinical trial. Obes Res 2005;13:615-625. [DOI: 10.1038/oby.2005.66]

18. Okura T, Nakata Y, Ohkawara K, Numao S, Katayama Y, Matsuo $\mathrm{T}$, et al. Effects of aerobic exercise on metabolic syndrome improvement in response to weight reduction. Obesity. 2012;15:2478-2484. [DOI: 10.1038/oby.2007.294]

19. Esteghamati A, Ashraf H, Rashidi A, Meysamie A. Waist circumference cut-off points for the diagnosis of metabolic syndrome in Iranian adults. Diab Res Clin Pract 2008;82:104107. [DOI: 10.1016/j.diabres.2008.07.009]

20. Damirchi A, Tehrani B, Alamdari K, Babaei P. Influence of aerobic training and detraining on serum BDNF, insulin resistance, and metabolic risk factors in middle-aged men diagnosed with metabolic syndrome. Clin J Sport Med 2014;24:513-519. [DOI: 10.1097/jsm.0000000000000082]

21. Bateman LA, Slentz CA, Willis LH, Shields AT, Piner LW, Bales CW, et al. Comparison of aerobic versus resistance exercise training effects on metabolic syndrome (from the Studies of a Targeted Risk Reduction Intervention Through Defined Exercise - STRRIDE-AT/RT). Am J Cardiol 2011:15;108:838-844. [DOI: 10.1016/j.amjcard.2011.04.037]

22. Grossmann M. Low testosterone in men with type 2 diabetes: significance and treatment. J Clin Endocrinol Metab. 2011;96:2341-2349. [DOI: 10.1210/jc.2011-0118]

23. Laaksonen DE, Niskanen L, Punnonen K, Nyyssonen K, Tuomainen T-P, Valkonen V-P, et al. The metabolic syndrome and smoking in relation to hypogonadism in middle-aged men: a prospective cohort study. J Clin Endocrinol Metab. 2005; 90:712-719. [DOI: 10.1210/jc.2004-0970]

24. Haring R, Ittermann T, Völzke H, Krebs A, Zygmunt M, Felix SB, et al. Prevalence, incidence and risk factors of testosterone deficiency in a population-based cohort of men: results from the study of health in Pomerania. Aging Male 2010; 13:247-257. [DOI: 10.3109/13685538.2010.487553]

25. Spark RF. Testosterone, diabetes mellitus, and the metabolic syndrome. Curr Urol Rep. 2007; 8:467-471. [DOI: 10.1007/ s11934-007-0050-4]

26. Isidori AM, Caprio M, Strollo F, Moretti C, Frajese G, Isidori A, et al. Leptin and androgens in male obesity: Evidence for leptin contribution to reduced androgen levels 1 . J Clin Endocrinol Metab 1999;84:3673-3680. [DOI: 10.1210/ jc.84.10.3673] 
27. Grossmann M, Thomas MC, Panagiotopoulos S, Sharpe $\mathrm{K}$, MacIsaac RJ, Clarke S, et al. Low testosterone levels are common and associated with insulin resistance in men with diabetes. J Clin Endocrinol Metab 2008;93:1834-40. [DOI: 10.1210/jc.2007-2177]

28. Pritchard J, Després J-P, Gagnon J, Tchernof A, Nadeau A, Tremblay A, et al. Plasma adrenal, gonadal, and conjugated steroids following long-term exercise-induced negative energy balance in identical twins. Metabolism 1999;48:11201127. [DOI: 10.1016/s0026-0495(99)90125-7]

29. Kraemer WJ, Ratamess NA. Hormonal responses and adaptations to resistance exercise and training. Sports Med 2005;35:339-361. [DOI: 10.2165/00007256-20053504000004]

30. Anagnostis $\mathrm{P}$, Athyros VG, Tziomalos K, Karagiannis A, Mikhailidis DP. The pathogenetic role of cortisol in the metabolic syndrome: a hypothesis. J Clin Endocrinol Metab. 2009;94:2692-2701. [DOI: 10.1210/endo.150.7.9998]

31. Starkweather AR. The effects of exercise on perceived stress and IL-6 levels among older adults. Biol Res Nurs 2007;8(3):186-94. [DOI: 10.1177/1099800406295990]

32. Vale RGdS, de Oliveira RD, Pernambuco CS, de Meneses YPdSF, Novaes JdS, de Andrade AFD. Effects of muscle strength and aerobic training on basal serum levels of IGF1 and cortisol in elderly women. Arch Gerontol Geriatr 2009;49:343-347. [DOI: 10.1016/j.archger.2008.11.011]

33. Grossmann M, Gianatti EJ, Zajac JD. Testosterone and type 2 diabetes. Curr Opin Endocrinol Diab Obes 2010;17:247256. [DOI: $10.1097 /$ med.0b013e32833919cf]

34. Travison TG, O’Donnell AB, Araujo AB, Matsumoto AM, McKinlay JB. Cortisol levels and measures of body composition in middle-aged and older men. Clin Endocrinol 2007;67:71-77. [DOI: 10.1111/j.1365-2265.2007.02837.x]

35. Sandeep S, Gokulakrishnan K, Velmurugan K, Deepa M, Mohan V. Visceral and subcutaneous abdominal fat in relation to insulin resistance and metabolic syndrome in nondiabetic south Indians. Indian J Med Res 2010;131:629.

36. Karolkiewicz J, Michalak E, Pospieszna B, Deskur-Śmielecka E, Nowak A, Pilaczyńska-Szcześniak Ł. Response of oxidative stress markers and antioxidant parameters to an 8-week aerobic physical activity program in healthy, postmenopausal women. Arch Gerontol Geriatr 2009;49:e67-e71. [DOI: 10.1016/j.archger.2008.09.001]

37. Pouliot M-C, Després J-P, Lemieux S, Moorjani S, Bouchard C, Tremblay A, et al. Waist circumference and abdominal sagittal diameter: best simple anthropometric indexes of abdominal visceral adipose tissue accumulation and related cardiovascular risk in men and women. Am J Cardiol 1994;73:460-8. [DOI: 10.1016/0002-9149(94)90676-9]
38. Gatti R, De Palo E, Antonelli G, Spinella P. IGF-I/IGFBP system: metabolism outline and physical exercise. J Endocrinol Invest 2012;35:699-707.

39. Rarick KR, Pikosky MA, Grediagin A, Smith TJ, Glickman EL, Alemany JA, et al. Energy flux, more so than energy balance, protein intake, or fitness level, influences insulin-like growth factor-I system responses during 7 days of increased physical activity. J Appl Physiol. 2007;103:1613-1621. [DOI: 10.1152/japplphysiol.00179.2007]

40. Lee I-T, Fu C-P, Lee W-J, Liang K-W, Lin S-Y, Wan C-J, et al. Brain-derived neurotrophic factor, but not body weight, correlated with a reduction in depression scale scores in men with metabolic syndrome: a prospective weight-reduction study. Diabetol Metab Syndr. 2014;6:1-7. [DOI: 10.1186/1758-5996-6-18]

41. Levinger I, Goodman C, Matthews V, Hare D, Jerums G, Garnham A, et al. BDNF, metabolic risk factors, and resistance training in middle-aged individuals. Med Sci Sports Exerc 2008;40:535. [DOI: 10.1249/mss.0b013e31815dd057]

42. Swift DL, Johannsen NM, Myers VH, Earnest CP, Smits JA, Blair SN, et al. The effect of exercise training modality on serum brain derived neurotrophic factor levels in individuals with type 2 diabetes. PloS One 2012;7:e42785. [DOI: 10.1371/journal.pone.0042785]

43. Bulló M, Peeraully MR, Trayhurn P, Folch J, Salas-Salvadó J. Circulating nerve growth factor levels in relation to obesity and the metabolic syndrome in women. Eur J Endocrinol 2007;157:303-310. [DOI: 10.1530/eje-06-0716]

44. Hristova M, Aloe L. Metabolic syndrome - neurotrophic hypothesis. Med Hypotheses 2006;66:545-549. [DOI: 10.1016/j. mehy.2005.08.055]

45. Lommatzsch M, Zingler D, Schuhbaeck K, Schloetcke K, Zingler C, Schuff-Werner P, et al. The impact of age, weight and gender on BDNF levels in human platelets and plasma. Neurobiol Aging 2005;26:115-23. [DOI: 10.1016/j.neurobiolaging.2004.03.002]

46. Terry Jr AV, Kutiyanawalla A, Pillai A. Age-dependent alterations in nerve growth factor (NGF)-related proteins, sortilin, and learning and memory in rats. Physiol Behav 2011;102:149-157. [DOI: 10.1016/j.physbeh.2010.11.005]

47. Manni L, Nikolova V, Vyagova D, Chaldakov GN, Aloe L. Reduced plasma levels of NGF and BDNF in patients with acute coronary syndromes. Int J Cardiol 2005;102:169-171. [DOI: 10.1016/j.ijcard.2004 .10.041]

48. Ejiri J, Inoue N, Kobayashi S, Shiraki R, Otsui K, Honjo $\mathrm{T}$, et al. Possible role of brain-derived neurotrophic factor in the pathogenesis of coronary artery disease. Circulation 2005;112:2114-2120. [DOI: 10.1161/CIRCULATIONAHA.104.476903] 
49. Sposato V, Manni L, Chaldakov G, Aloe L. Streptozotocinin-duced diabetes is associated with changes in NGF levels in pancreas and brain. Arch Ital Biol 2007;145:87-97. [PMID:17639781]

50. Larrieta M, Vital P, Mendoza-Rodríguez A, Cerbón M, Hiriart M. Nerve growth factor increases in pancreatic beta cells after streptozotocin-induced damage in rats. Exp Biol Med (Maywood, NJ) 2006;231:396. [PMID: 16565435]

51. Rasmussen P, Brassard P, Adser H, Pedersen M, Leick L, Hart E, et al. Evidence for a release of brain-derived neurotrophic factor from the brain during exercise. Exp Physiol 2009;94:1062. [DOI: 10.1113/expphysiol.2009.048512]
52. Neeper SA, Gómez-Pinilla F, Choi J, Cotman CW. Physical activity increases mRNA for brain-derived neurotrophic factor and nerve growth factor in rat brain. Brain Res 1996;726:749-756. [DOI: 10.1016/0006-8993(96)00273-9]

53. Knaepen K, Goekint M, Heyman EM, Meeusen R. Neuroplasticity - Exercise-induced response of peripheral brainderived neurotrophic factor. Sports Med 2010; 40:765-801. [DOI: 10.2165/11534530-000000000-00000]

54. Sornelli F, Fiore M, Chaldakov GN, Aloe L. Adipose tissuederived nerve growth factor and brain-derived neurotrophic factor: results from experimental stress and diabetes. Gen Physiol Biophys 2009; 28:179-183. [PMID: 19893098] 